\title{
Human resource practices, organizational commitment and intention to stay
}

\author{
Janet Chew \\ School of Business and Informatics (NSW), Australian Catholic University, \\ Sydney, Australia, and \\ Christopher C.A. Chan \\ Atkinson Faculty of Liberal \& Professional Studies, \\ School of Administrative Studies, York University, Toronto, Canada
}

\begin{abstract}
Purpose - The purpose of this paper is to examine the impacts of key human resource (HR) practices on permanent employees' organizational commitment and intention to stay. These practices include facilitating of person-organization fit (P-O fit), designing effective remuneration and recognition, creating sufficiently challenging assignments, and implementing training and career development.

Design/methodology/approach - The study was carried out in three phases. First, 13 experts (e.g. academics, HR managers and organizational psychologists) were interviewed using the Delphi technique. Second, in-depth interviews with $12 \mathrm{HR}$ managers were conducted. Third, 457 employees from nine Australian organizations responded to a survey. Structural equation modeling was used to test the hypotheses.

Findings - Organizational commitment was positively affected by P-O fit, remuneration, recognition, and an opportunity to undertake challenging employment assignments. Intention to stay was significantly related to P-O fit, remuneration, recognition, training and career development. Surprisingly, training and career development was not significantly related to organizational commitment and challenging assignment was not significantly related to intention to stay.

Originality/value - This paper contributes to existing knowledge by testing HR practices in large public and private Australian organizations, which are impacted by demographic changes, increasing dependence on outsourcing, and industrial relations reforms. Thus, the results of this study will provide practitioners with better insights into some practices that could elevate organizational commitment and retention of employees.
\end{abstract}

Keywords Permanent workers, Employee attitudes, Job satisfaction, Human resource management

Paper type Research paper

\section{Introduction}

Two salient ongoing organizational issues faced by managers include eliciting the commitment of employees and staff retention. For organizations, the high cost of recruitment and selection (Pfeffer, 1998), the lag and productivity loss during the assimilation period (Davies, 2001), the likely loss of business opportunity (McCallum, 1988; Walker, 2001), poor customer relationship (Clarke, 2001; Messmer, 2000), and hidden cost of loss productivity (Das, 2002) have subsequently highlighted the

The authors thank the anonymous reviewers for their beneficial and constructive comments. 
importance of retaining committed employees as an aspect of survival for organizations. In response to these potential problems, many forward-thinking organizations are striving to create a positive organizational climate in an attempt to retain valuable employees through various human resource management (HRM) initiatives. Some of these practices include ensuring that there is a good fit between the individual employees' values and the organization's values in the recruitment and selection phase (Van Vianen, 2000), providing equitable remuneration that reflects performance (Boyd and Salamin, 2001; Parker and Wright, 2000), recognizing efforts and contributions made by individuals (Davies, 2001), providing employees with sufficiently challenging and interesting work (Kraut and Korman, 1999), and providing opportunities for training and career development (Wetland, 2003). These efforts are aimed at improving human resource (HR) practices and workplace relations and, consequently, organizational performance via the shaping of employees' attitudes and behaviors (Whitener, 2001).

Although there have been previous studies on best practices in HRM (Barney and Wright, 1998), most of these studies have been fragmented in identifying an effective mix of practices that could improve organizational commitment and intention to stay. Moreover, there is a noticeable lack of empirical examination of large Australian organizations with regard to their HR practices on commitment and retention. The growth and development of Australian organizations have been different from the US due to changes in the Australian workplace that are brought about mainly by recent demographic changes (especially an influx of migrants from countries in south-east Asia, the middle-east and Africa), changes in HRM practices (e.g. increasing use of outsourcing) and current industrial relations reforms. According to an Australian Bureau of Statistics Report (ABS, 2001), the Australian workforce has changed dramatically in terms of age, gender, ethnic and racial composition, family structure, and job expectations. As a result, such socio-cultural developments have had significant impacts on the nature and operations of organizations (Ferris et al., 1999; Kemske, 1998) especially in the management of HR (e.g. recruitment and selection, training and development and performance management programs). These contrasting changes in the business environment of Australia begs the questions "Are these best HR practices, which are derived mainly from the US, universally applicable?" and "How do Australian practitioners perceive the effectiveness of such HR practices?" If these HR practices are considered ineffective, are they reluctantly adhering to the universal approach (the American model) or are they adopting existing model to fit the Australian business environment? Therefore, what is the retention strategy of Australian organizations?

With the scarcity of Australian empirical studies, there is a need to advance the currently available knowledge to identify an effective mix of practices that are relevant in an Australian context. An attempt to develop an initial understanding of the HR issues pertaining to retention practices in large Australian organizations is done through Delphi and interview studies. In this case, a large organization is defined as an organization with more than 500 employees. An expert panel made up of four HR practitioners, six senior faculty members and three organizational psychologists participated in the Delphi study. Open-ended questions pertaining to HR practices and retention were derived from a review of the literature. The preliminary Delphi study questions were: 
(1) How do you think HR practices of Australian organizations influence the retention of permanent and non-permanent employees? Please explain your views.

(2) Kindly identify the HR factors/elements that influence the decision of employees to stay with an organization in Australia. Please explain why you believe that each factor influences retention.

(3) With regards to current HRM practice, do you think Australian organizations adopt one standardized practice for every employee within the firm (a holistic approach) or apply different HR practices for different types of employees? Can you give examples to illustrate your answers?

The panel members identified a number of issues that were important to the permanent employees, namely satisfying work environment, training and career development opportunities, reward and recognition, good pay and conditions, good working relationships, good resources, state of the art equipment, status, challenging job and autonomy. The HR practices are summarized in the Appendix. After the Delphi study, face-to-face interviews with $12 \mathrm{HR}$ practitioners ( 6 females and 6 males), each lasting 30 and $45 \mathrm{~min}$, were conducted. These HR practitioners came from 12 organizations ( 2 from the engineering sector, 3 from the health care sector, 3 from the higher education sector, 3 from the public sector, and 1 from the manufacturing sector). Also, the organizations had more than 10 years of establishment to ensure that there was an existence of developed HR systems (Jackson and Schuler, 1995). Those participants were required to rank the five top most important HR practices (shown in the Appendix). Effective selection, reward and recognition of employee, provision of effective training, challenging employment structures and opportunities, and equity of compensation and benefits were considered to be the top five $\mathrm{HR}$ practices that were considered to be relevant for retention. Information obtained was provided to all participants in another round of ranking, which was done to provide the respondents with an opportunity to refine their opinions and achieve some consensus. Overall, this initial investigation revealed four crucial areas in HR practices (i.e. person-organization fit (P-O fit), remuneration and recognition, training and career development, and challenging assignment) that were relevant to the retention of employees.

On a practical level, the results of this study will hopefully provide practitioners with better insights into some practices that could be used to elevate organizational commitment and retention of employees. It would also offer an opportunity for organizations to eliminate the practices that are obsolete. To achieve these aims, we examined permanent employees' perceptions of the efficacy of P-O fit, remuneration, recognition, challenging assignments, provision of training and career development opportunities on organizational commitment and intention to stay in nine Australian organizations. An investigation of these HRM-related factors that affect employee commitment and decision to stay is likely to contribute to the currently available knowledge, as the role of organizations in affecting employee attitudes is not adequately addressed (Peterson, 2004).

Theoretical background and hypothesis development

A review of the literature reveals that there are three main perspectives on HRM practices. The universalistic approach states that there is an identifiable set of best 
practices, which when executed could lead to organizational improvements (Kochan and Osterman, 1994; Pfeffer, 1994). The contingency approach attempts to contextualize the various HRM practices to different organizational settings and strategies (Arthur, 1994; Youndt et al., 1996). The configurational approach argues that a good fit between various HRM practices and organizational strategy would improve the HRM-firm performance relationship (Becker and Gerhart, 1996). Regardless of these different ideologies, there are a number of common HRM practices that are overlapping in the three approaches in improving organizational commitment and intention to stay. In our study, we have focused on P-O fit, remuneration and recognition, opportunity to work on challenging assignments, and access to training and career development, as these factors are common across the three approaches in improving commitment and retention (Beck, 2001; Clarke, 2001; Parker and Wright, 2000; Stein, 2000; Tsui et al., 1997). Moreover, these factors were identified to be important HR practices in the Delphi and interview stages of our study.

\section{Person-organization fit}

The concept of P-O fit is based on the idea that organizational productivity and individual performance will improve as a result of congruity between an individual's and the organization's values, beliefs and goals (Chatman, 1991; Schneider et al., 1995). Other researchers (e.g. O'Reilly et al., 1991) treat P-O fit as the extent of compatibility between the person and the organizational culture. Although previous studies have typically distinguished between subjective and objective P-O fit (Erdogan and Bauer, 2005; Huang et al., 2005), we have focused on subjective P-O fit for practicality reasons. Given the implications of P-O fit on performance-related issues (i.e. self and objective measures of work performance; Bretz and Judge, 1994), many recruiters are focusing on the careful selection of suitable candidates who are likely to fit into the organization so as to ensure that these potential employees are likely to succeed in the organization (Cable and Judge, 1997), which in turn would promote organizational success. In a recent meta-analysis conducted by Kristof-Brown et al. (2005), P-O fit was moderately related to contextual performance $(r=0.27)$, which explains the need for people to find meaning in the work they are doing.

P-O fit has been shown to be related to job attitudes (Kristof-Brown et al., 2005). A good P-O fit suggests that the individuals' needs are mainly satisfied and the organization's requirements are met (Kristof, 1996; Lauver and Kristof-Brown, 2001). Thus, employees may feel obliged to exhibit greater commitment and there is less incentive to leave the organization (O'Reilly et al., 1991). These findings may be explained by the concept of reciprocity or social exchange (Blau, 1964). For instance, as long as individuals and the organization are contented with the needs, expectations, desires or preferences, employees will continue to commit themselves and stay with the organization in order to receive those benefits. Alternatively, employees who perceive that their personal expectations are not met may be less committed to the organization and may even consider leaving. Studies by Becker and Billings (1993), Hollenbeck (1989), Lauver and Kristof-Brown (2001), and Vandenberghe (1999) have provided some empirical support for this belief, showing that P-O fit is positively associated with organizational commitment and is negatively related to turnover intention. Based on previous research evidence, we expect that: 
H1. Person-organization fit is positively related to organizational commitment and intention to stay.

\section{Remuneration and recognition}

Remuneration and recognition are important contractual and implied agreements between an employer and an employee. According to Willis (2000, p. 20), compensation is "the most critical issue when it comes to attracting and keeping talents." As a result, some companies may even provide remuneration packages that are well above the market rate to attract and retain critical talents (Parker and Wright, 2000), which often include special pay premiums, stock options or bonuses. In addition, some leading edge firms have used profit sharing and group-based incentive pay (Bassi and Van Buren, 1999). Although compensation provides some recognition (as in the case of pay for performance), non-monetary recognition is also important (Park et al., 1997). Examples of non-monetary recognition include praises from managers, team members and customers.

Although pay is recognized as a potential antecedent of organizational commitment and intention to stay, we recognize that pay alone will not be sufficient. For example, low pay might drive an employee out, but high pay might not necessarily keep them. There might be other intrinsic and extrinsic factors that may influence an employee's decision to exert greater commitment or remain with the employer. An important factor underpinning the relationship between pay and job attitudes (such as organizational commitment and intention to stay) is the perception of equity of compensation (Roberts et al., 1999). Thus, a central belief in the use of compensation is that money has the potential to influence behavior (Parker and Wright, 2000). Likewise, employees may express greater commitment and tend to remain with the organization when they feel that their capabilities, efforts and performance contributions are recognized and appreciated (Davies, 2001; Mercer Report, 2003). Hence, we expect that:

H2. Remuneration and recognition positively affect organizational commitment and intention to stay.

Opportunities to work on challenging assignments

Organizational theorists have suggested that job enrichment initiatives need to be created for a productive workplace to exist. Individuals who prefer challenging assignments in their career tend to be high in cognitive abilities (Trank et al., 2002). One way of achieving this is to focus on rapid promotion so these high achievers can work on more challenging assignments (Frank and Cook, 1995; Kanfer and Heggestad, 1997). In addition, the provision of adequate performance feedback is important for the creation of a productive environment in which employees can achieve their personal and organizational objectives (Furnham, 2002). Parallel to efforts in providing job challenges is career development, which enables employees to build breadth of experience to assume leadership roles within the organization (Ferguson, 1990). Such an effort starts from job design, where broad career goals are defined, where there is flexible job descriptions, and where training and career development opportunities are provided.

An opportunity to work on challenging assignment has been shown to be positively related to organizational commitment and intention to stay. For example, studies (e.g. Idaszak and Drasgow, 1987; Pil and Macduffie, 1996; Price and Mueller, 1981; Udo et al., 1997; Workman and Bommer, 2004) involving technical workers have found 
that employees who are offered challenging, exciting and interesting work tend to be more involved and satisfied, and are in turn more committed to their organization and are less likely to leave their organization. One possibility why employees might hold such attitudes is that career management leads to a fulfillment of psychological contract (Sturges et al., 2005). This belief is based on the social exchange theory (Blau, 1964), where as long as an organization is able to fulfill an employee's expectations of career mentoring and development, the employee will reciprocate by showing greater commitment and lower turnover intention (Chen et al., 2004). For these reasons, we propose the following hypothesis:

H3. Opportunities to work on challenging assignments positively affect organizational commitment and intention to stay.

\section{Opportunities for training and career development}

The training and development of employees is increasingly recognized as an important aspect of best HRM practices. Training and development are commonly considered to be different forms of human capital investment for individual and organizational improvements (Goldstein, 1991; Wetland, 2003). An area where training may be used is in the enhancement of job specific skills. Another area of focus for training is in the correction of deficiencies in job performance and development that may be provided to employees with abilities the organization might need in the future (Gold, 2001; Gomez-Mejia et al., 1995; Wood and De Menezes, 1998). Findings by Black and Lynch (1996) indicate that larger employers, establishments with productive systems, and those that use more physical capital are more likely to train their employees. Moreover, firms that provide more benefits and have innovative work practices are more likely to invest in their employees (Wiens-Tuers, 2001).

Although conventional wisdom states that trained individuals become more marketable and consequently might leave the organization at the first instance, contemporary studies have demonstrated that training and development affect job attitudes. For example, studies of employee commitment among hospital administrators, nurses, service workers, clerical workers, scientists and engineers revealed that organizations that were able to fulfill their employees' career aspirations had marked effect on organizational commitment (Detoro and McCabe, 1997; Marchington and Wilkinson, 1997; Storey and Sisson, 1993). Consistent with this finding, in a study that involved a manufacturing plant, internal mobility and promotion from within, company sponsored training and development, and job security were important influencers of employee commitment (Bassi and Van Buren, 1999). In addition, when the training and development needs of employees and employers are met, the more likely employees will stay in their organizations (Bassi and Van Buren, 1999; Sheridan, 1992; Wood, 1999):

H4. Training and career development positively affect organizational commitment and intention to stay.

\section{Method}

Procedures

In total, 800 questionnaires were distributed to the employees via the internal mail system by the HR manager. These questionnaires were paper and pencil based. 
Participation was entirely voluntary and the participants were given company time to complete the questionnaires. The completed questionnaires were forwarded to the HR manager via the internal mail system to maintain anonymity. One of the researchers collected the completed questionnaires a week after distribution. In total, 457 employees responded, generating an overall response rate of 57.1 percent.

\section{Participants}

The participants were full-time and permanent employees of 9 large public and private organizations. The organizations were from various industry sectors, such as health care (2), higher education (3), public sector (3), and manufacturing (1). Each organization has more than 500 employees. There was a fairly even split between female ( 45 percent) and male (55 percent) participants. There was a fairly even distribution across various age groups (e.g. 21 percent between 20 and 29 years, 21 percent between 30 to 39 years, 26 percent between 40 and 49 years, and 32 percent who were more than 50 years old). These respondents consisted of 15 percent administrator, 5 percent IT technician, 15 percent manager, 2 percent librarian, 16 percent lecturer, 3 percent accountant, 11 percent engineer, 1 percent HR officer, 1 percent physician, 1 percent researcher, 12 percent nurse, 3 percent veterinary personnel, and 15 percent navy officer and personnel.

\section{Measures}

The HR practices were measured with scales for P-O fit, remuneration and recognition, opportunities for training and career development, and opportunities to work on challenging assignments. The two outcomes included organizational commitment and intention to stay. All items were scored with a seven-point scale, ranging from (1) strongly disagree to (7) strongly agree.

$P$-O fit was measured via a four-item scale developed by Netemeyer et al. (1997). This construct reflects the person-organization element of selection (Cable and Judge, 1997). A sample item includes "I feel that my personal values are a good fit with the organizational values." The Cronbach alpha for P-O fit was 0.75 .

Remuneration and recognition was measured with a 5-item scale that focused on intrinsic and extrinsic rewards (Cammann et al., 1979; Seashore et al., 1982). Extrinsic reward measures were designed to measure the employee's view of the economic rewards from his/her job, which includes pay, benefits, and job security. The scale also measured the degree to which intrinsic rewards such as recognition were present in the organization. A sample item includes "Employees are given positive recognition when they produce high quality work." The Cronbach alpha for remuneration and recognition was 0.72 .

Training and career development was measured via a four-item scale developed by Broadfoot and Ashkanasy (1994). This scale focused on whether the organization expended sufficient effort in providing opportunities for people to develop their skills and evaluated the adequacy of the training. A sample item includes "People are properly orientated and trained upon joining this organization." The Cronbach alpha for training and career development was 0.86 .

Opportunities to work on challenging assignments was measured with a 5-item scale that was derived from the challenging assignments section of the Job Diagnostic Survey (Hackman and Oldham, 1975). A sample item includes "Employees are offered 
more challenging work within the organization." The Cronbach alpha for challenging assignments was 0.85 .

Organizational commitment was measured using the abridged 9-item organizational commitment questionnaire (OCQ) scale developed by Mowday et al. (1979) in order to take into account criticism of the original 15-item scale (O'Reilly and Chatman, 1986; Reichers, 1985). The OCQ is a measure of affective commitment. Three items had to be removed because of poor item-to-total correlations (i.e. "There is little to be gained by sticking with this organization indefinitely", "I could just as well be working for a different organization if the type of work was similar", "I find it difficult to agree with this organization's policies"). The resulting Cronbach alpha for organizational commitment was 0.89 .

Intention to stay was measured with a four-item scale consisting of items adapted from the Michigan Organizational Assessment Questionnaire (Cammann et al., 1979; Seashore et al., 1982) and the Lyons' Propensity to Leave scale (Lyons, 1971). A sample item includes "I plan to work at my present job for as long as possible." An item that had poor item-to-total correlation was removed (i.e. "I will most certainly look for a new job in the near future"). The resulting Cronbach alpha for intention to stay was 0.76 .

\section{Control variables}

Previos studies have identified age, gender, occupation and industry to correlate with organizational commitment and intention to stay (Huang et al., 2006; Paré and Tremblay, 2007; Taplin and Winterton, 2007). The four control variables were coded as follows: age $(1=20-29$ years, $2=30-39$ years, $3=40-49$ years, $4=50$ years or older $)$ gender $(1=$ male, $2=$ female $)$, occupation $(1=$ administrator, $2=$ information technology technician, $3=$ manager, $4=$ librarian, $5=$ faculty member, $6=$ accountant, $7=$ engineer, $8=\mathrm{HR}$ personnel, $9=$ physician, $10=$ researcher, $11=$ nurse, $12=$ veterinary personnel, $13=$ navy officer, $14=$ navy personnel), and industry $(1=$ university sector, $2=$ health care sector, $3=$ public sector, $4=$ private sector).

\section{Results}

Table I shows the means, standard deviations, reliability coefficients, and correlation coefficients of the variables. The mean scores indicate an average level of utilization of various HR practices. As shown in Table I, the HR practices are correlated with organizational commitment and intention to stay.

Before testing the hypotheses, we conducted a series of confirmatory factor analyses of the HR practices with AMOS. The initial model fit was marginal $\left(\chi^{2}=429.31\right.$, $\mathrm{df}=129 ; \quad$ normed $\quad \chi^{2}=3.33 ; \quad \mathrm{NFI}=0.89 ; \quad$ TLI $=0.91 ; \quad$ CFI $=0.922$; RMSEA $=0.07$ ). After allowing the errors of two items in "Remuneration and recognition" to be correlated (i.e. "This organization pays well" and "This organization offers a good benefits package compared to other organizations."), the fit indices improved $\left(\chi^{2}=346.93, \mathrm{df}=128 ;\right.$ normed $\chi^{2}=2.71 ; \mathrm{NFI}=0.91 ; \mathrm{TLI}=0.93$; $\mathrm{CFI}=0.94$; RMSEA $=0.06$ ). Allowing for the correlation of errors is deemed appropriate because the two items are measuring the same construct.

Next, another set of confirmatory factor analyses of organizational commitment and intention to stay were performed. The initial model indicated a marginal fit $\left(\chi^{2}=208.27, \mathrm{df}=34 ;\right.$ normed $\chi^{2}=6.13 ; \mathrm{GFI}=0.91 ; \mathrm{AGFI}=0.86 ; \mathrm{NFI}=0.91$; 


\begin{tabular}{|c|c|c|c|c|c|c|c|c|c|c|c|c|}
\hline & Mean & $\mathrm{SD}$ & 1 & 2 & 3 & 4 & 5 & 6 & 7 & 8 & 9 & 10 \\
\hline Age & 2.68 & 1.13 & & & & & & & & & & \\
\hline Gender & 1.45 & 0.50 & 0.07 & & & & & & & & & \\
\hline Industry & 2.02 & 1.02 & $-0.37^{* * *}$ & $-0.24^{* * *}$ & & & & & & & & \\
\hline Occupation & 8.23 & 5.86 & $-0.30^{* * *}$ & -0.01 & $0.25^{* * *}$ & & & & & & & \\
\hline Person-organization fit & 4.39 & 1.24 & 0.00 & $0.12 *$ & -0.08 & -0.02 & $(0.75)$ & & & & & \\
\hline Remuneration and recognition & 3.83 & 1.10 & -0.04 & 0.03 & -0.09 & -0.05 & $0.45^{* * *}$ & $(0.72)$ & & & & \\
\hline Challenging assignment & 4.75 & 1.17 & 0.06 & $0.10^{*}$ & $-0.16^{* *}$ & 0.01 & $0.54^{* * *}$ & $0.54^{* * *}$ & $(0.85)$ & & & \\
\hline Training and career development & 4.11 & 1.44 & 0.05 & $0.11^{*}$ & $-0.09^{*}$ & -0.04 & $0.51^{* * *}$ & $0.50 * * *$ & $0.65^{* * *}$ & $(0.86)$ & & \\
\hline Organizational commitment & 4.54 & 1.27 & $0.10^{*}$ & $0.15 * *$ & -0.09 & 0.02 & $0.66 * * *$ & $0.50^{* * *}$ & $0.59 * * *$ & $0.61^{* * *}$ & $(0.89)$ & \\
\hline Turnover intention & 4.34 & 1.63 & $0.25^{* * *}$ & $0.12^{*}$ & $-0.13^{* *}$ & -0.07 & $0.38 * * *$ & $0.43^{* * *}$ & $0.46^{* * *}$ & $0.40 * * *$ & $0.62 * * *$ & $(0.76)$ \\
\hline
\end{tabular}

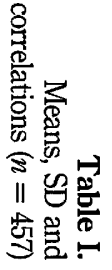


$\mathrm{TLI}=0.90 ; \mathrm{CFI}=0.93 ;$ RMSEA $=0.11$ ). After allowing the errors of two items in organizational commitment (i.e. "I am willing to put in a great deal more effort than normally expected to help this organization be successful" and "I really care about the fate of this organization") to be correlated, the fit indices improved $\left(\chi^{2}=123.58\right.$, $\mathrm{df}=33$; normed $\chi^{2}=3.75$; GFI $=0.95$; AGFI $=0.91$; NFI $=0.95$; $\mathrm{TLI}=0.95$; $\mathrm{CFI}=0.96$; RMSEA $=0.08$ ). Two more items in organizational commitment were allowed to be correlated (i.e. "This organization really inspires the very best in me in the way of job performance" and "I find that my values and this organization's values are very similar"), and the fit indices improved further $\left(\chi^{2}=80.18, \mathrm{df}=32\right.$; normed $\chi^{2}=2.51 ; \quad \mathrm{GFI}=0.97 ; \mathrm{AGFI}=0.94 ; \mathrm{NFI}=0.97 ; \mathrm{TLI}=0.97 ; \mathrm{CFI}=0.98 ;$ RMSEA $=0.06$ ). After allowing the errors of yet two more items in organizational commitment (i.e. "I am proud to tell others that I am part of this organization" and "I really care about the fate of this organization"), the fit indices improved to $\left(\chi^{2}=62.71\right.$, $\mathrm{df}=31$; normed $\chi^{2}=2.02$; GFI $=0.97$; AGFI $=0.95$; NFI $=0.97$; TLI $=0.98$; $\mathrm{CFI}=0.99$; RMSEA $=0.05$ ). These correlations are deemed appropriate, as the items measure organizational commitment.

Structural equation modeling was employed to test the hypothesized relationships. The fit indices suggest a good model fit $\left(\chi^{2}=1,114.49\right.$, $\mathrm{df}=421$; normed $\chi^{2}=2.65$; $\mathrm{TLI}=0.89 ; \mathrm{CFI}=0.90 ; \mathrm{RMSEA}=0.06$ ). The results of structural equation modeling are presented in Table II. Consistent with previous studies, age is found to be significantly related to organizational commitment and intention to stay (Bayazit et al., 2003; Schnake et al., 2007) and occupational group is related to organizational commitment (Preuss and Lautsch, 2002). Providing support for H1, P-O fit was positively related to organizational commitment and intention to stay. $\mathrm{H} 2$ received support in terms of remuneration and reward being positively related to organizational commitment and intention to stay. H3 predicted that opportunities to work on challenging assignments would positively affect organizational commitment and intention to stay. While the parameter estimates for challenging assignments and organizational commitment was significant, the path between challenging assignments and intention to stay was not significant. Therefore, $H 3$ is partially supported. Similarly, $H 4$ is partially supported, as training and career development was not significantly related to organizational commitment but was a significant predictor of intention to stay.

Table II.

Results of structural equation modeling $(n=457)$

\begin{tabular}{|c|c|c|c|c|}
\hline Variables & $\begin{array}{c}\text { Organizational } \\
\text { commitment }\end{array}$ & $\begin{array}{l}\text { Intention } \\
\text { to stay }\end{array}$ & $\begin{array}{c}\text { Organizational } \\
\text { commitment }\end{array}$ & $\begin{array}{l}\text { Intention } \\
\text { to stay }\end{array}$ \\
\hline Age & 0.09 & $0.31^{* * *}$ & $0.12^{*}$ & $0.37^{* * *}$ \\
\hline Gender & $0.15 * *$ & $0.12^{*}$ & $0.05^{\text {n.s. }}$ & $0.06^{\text {n.s. }}$ \\
\hline Occupation & 0.06 & 0.02 & $0.08^{*}$ & $0.03^{\text {n.s. }}$ \\
\hline Industry & -0.04 & -0.01 & $0.03^{\text {n.s. }}$ & $0.05^{\text {n.s. }}$ \\
\hline Person-organization fit & & & $0.53^{* * *}$ & $0.17^{*}$ \\
\hline Remuneration and recognition & & & $0.29^{* * *}$ & $0.45^{* * *}$ \\
\hline Challenging assignment & & & $0.15^{*}$ & $-0.06^{\text {n.s. }}$ \\
\hline Training and career development & & & $0.03^{\mathrm{n} . \mathrm{s}}$ & $0.15^{\text {n.s. }}$ \\
\hline
\end{tabular}




\section{Discussion}

Previous studies by social exchange theorists suggest that employees interpret HR practices as indicative of the personified organization's commitment to them (Eisenberger et al., 1990; Setton et al., 1996). Based of the employees' perception of the organization's commitment, they reciprocate by adjusting their attitudes to the organization. Some researchers suggest that for positive work experiences to increase organizational commitment and to reduce turnover intention, employees must believe that such experiences are a result of effective management policies and practices (Parker and Wright, 2000). Overall, the results of this study offer a number of salient implications for establishing employee commitment and retention practices.

The results of this study revealed that organizational commitment and intention to stay were significantly related to P-O fit. Consistent with previous research (e.g. Abbott et al., 2005; Finegan, 2000; Kristof-Brown et al., 2005; Schneider, 1987), individuals may be drawn to exert more organizational commitment when they perceive that their values are more aligned with the organization's values. Thus, the organization should not only match the job requirements with the person's knowledge, skills and abilities, but should also carefully match the person's personality and values with the organization's values and culture. Also consistent with the literature is the finding that P-O fit increases an employee's intention to stay (Chatman, 1991; Lauver and Kristof-Brown, 2001; Vandenberghe, 1999). Preferences to work for particular companies are frequently based on the congruence between individuals' perceptions of themselves and an organization's reputation. Individuals may place themselves in companies that best suit their characteristics and are more likely to remain in organizations that provide a positive match (Schneider, 1987; Van Vianen, 2000). Understandably, employees who perceive a fit with the organization are more likely to stay than those who are less suited (Lee et al., 1992).

Similarly, remuneration and recognition positively predicted organizational commitment and intention to stay. Since the underlying assumption is that money can influence behavior, a fair remuneration is understood to be the cornerstone of the contractual and implied agreement between employees and employers (Parker and Wright, 2000). The employee performs work on the job with the understanding that the employer will reciprocate by providing compensation and other positive considerations, which is consistent with the work on social exchange theory by Whitener (2001). According to a study by Mercer Report (2003), employees will stay if they are rewarded fairly and adequately. Employees tend to remain with the organization when they feel their capabilities, efforts and performance contributions are recognized and appreciated (Davies, 2001). Employers are increasing their commitment to the use of rewards as essential elements of talent management programs. Hence, an increasingly important consideration for companies is to use their reward budget effectively to differentiate the rewards of the top performers.

This study also examined the role of providing a challenging assignment on organizational commitment and intention to stay. While the positive relationship between challenging assignment and organizational commitment is consistent with past studies (e.g. Ferguson, 1990; Furnham, 2002; Walker, 2001), an employee's intention to stay is not significantly affected by the degree of challenge provided by the assignment. Some studies reveal that employees often commit to a firm that enables them to best utilize their skills and abilities and to an organization that provides an 
environment that appropriately matches their personal attributes (Kristof, 1996; Withers, 2001). Several studies on productivity emphasize that high talent individuals often seek work that is creative and challenging (Shepherd and Mathews, 2000; Jardine and Amig, 2001). On the contrary, according to Phillips (1997), failure by organizations to provide their employees with opportunities to develop new skills would result in employees reporting negative feelings and attitudes toward the organization. The non-significant association between opportunities to work on challenging assignments and intention to stay is surprising because Ferguson (1990) argues that companies like IBM and General Electric integrate succession planning to provide a sense of growth for employees. Thus, one possible explanation for the non-significant finding is that there is a lack of succession planning in place. Another plausible explanation is that succession planning is normally applicable to upper level management and our sample is heterogeneous (i.e. various professions and various organizational levels).

Finally, the effects of training and career development on organizational commitment and intention to stay were examined. Surprisingly, employees may not necessarily increase commitment to their organizations as the provision of training and development increases. This non-significant association could be due to two reasons. First, there may be a mismatch between training and career development and personal growth, which might have an effect on organizational commitment. Several studies on organizational commitment suggest that an employer's ability to provide relevant and effective training has a marked effect on employee commitment to their organization (Bassi and Van Buren, 1999; Detoro and McCabe, 1997; Marchington and Wilkinson, 1997). Thus, these organizations may need to identify suitable training and career development needs for individuals (Wetland, 2003). The second reason may be explained by organizational constraints such as time, personnel, budget, training facilities, materials equipment, and the attitude of senior management (Gomez-Mejia et al., 1995). These restrictions have the potential to impact on the training content and consequently organizational commitment. Training and career development has significant positive association with intention to stay, which is consistent with the results of existing literature (e.g. Lauri et al., 1996; Oakland and Oakland, 2001; Jones et al., 2001; Vorhies and Harke, 2000). From the employee's point of view, training is a symbol of the employer's commitment to their staff (Storey and Sisson, 1993). If the training involves the development of skills specific to the organization, it is likely to result in greater productivity for the firm, which in turn may raise the wages above what the employee will obtain elsewhere thus providing an incentive to stay (Frazis et al., 1998).

Several limitations in this study should be taken into consideration. One of the limitations is that this study has only investigated employees' intention to stay, which is an affective response and not an objective measure. Another limitation is that the nature of the data only permits a cross-sectional analysis and, thus, only inferences (and not causality) can be established. This study has investigated a limited range of industries, which included higher education, health care, public sector and manufacturing. Poorly worded questions, leading questions or selective interpretation of the results during the Delphi phase might affect the results. However, this limitation was addressed with the use of a focus group to clarify the responses. Participant dropout can pose a problem in a Delphi study (Linstone and Turoff, 1975). For instance, initially, 17 experts agreed to participate in the Delphi 
study, but only 13 responded. However, the level of dropout is considered minuscule. The use of in-depth interviews to probe complex answers may be prone to inaccuracy due to the sensitive and confidential nature of the information sought. To overcome this potential problem and to reduce the reluctance to share the information freely, a semi-structured interview style was selected to elicit the responses and the participants' confidentiality was assured. Finally, the use of perceptual data may introduce common method bias, but an analysis of variance of the demographic variables did not reveal any significant difference.

Several extensions to this study may provide further insights into the complex nature of employee commitment and intention to stay. An obvious extension is to conduct a longitudinal study to assess the efficacy of the commitment and retention model. Such a study has great potential to reveal if intention to stay, measured at one point in time, is associated with beliefs and outcomes at a later point in time. A longitudinal study would be able to further examine the changing nature of organizational commitment and intention to stay throughout an employee's tenure, with emphasis on management's policies and reactions to maintain equity and fairness in the employer-employee dynamics. Furthermore, future studies should consider the associations between HR practices and other forms of commitment (e.g. continuance and normative commitment). Some employees may feel more committed and obligated to remain in an organization that has invested in them. Also, employees who have invested a great deal of time, effort and energy in an organization may be reluctant to leave (Meyer et al., 2002). Other aspects of the work environment, such as formalization, socialization role ambiguity, need to be examined to provide further insights into the employment relationship. Further testing of this model in other industries would also be beneficial and may help ascertain to what degree various HRM practices affect commitment and intention to stay. Since the present study only deals with permanent employees, the efficacy of this model can also be tested with samples in alternative employment arrangements, such as part-time, casual and contract workers.

In conclusion, this study has theoretical and practical implications. For example, in agreement with the extant literature, P-O fit, remuneration and recognition were important antecedents of commitment and intention to stay. Hence, there is some support for the efficacy of these practices in enhancing employee commitment and intention to stay in Australian organizations. However, readers should not interpret these results as advocacy for selecting individuals solely on P-O fit, which is potentially a discriminatory practice, and results in an organization hiring clones. The decision to select suitable candidates on P-O fit should be balanced with merit based hiring decisions and diversity management. In exchange for an opportunity to work on a challenging assignment, employees become affectively committed to their organizations but remain impartial when intention to stay is considered. Although employees who are provided with more opportunities for training and career development may not necessarily increase their affective commitment, they are more likely to stay. While most of these findings are consistent with previous studies, the two non-significant associations that are found challenge academics and practitioners to delve deeper into the complex nature of organizational commitment and intention to stay. In spite of the differences between Australia and the USA that prompted this investigation (e.g. firm growth, socio-cultural changes, industrial relations reform and 
changes in HRM practices), the results of statistical analyses and the HR issues identified by the Delphi and interview panel members foreshadowed a convergence towards best $\mathrm{HR}$ practices.

\section{References}

Abbott, G.N., White, F.A. and Charles, M.A. (2005), "Linking values and organizational commitment: a correlational and experimental investigation in two organizations", Journal of Occupational \& Organizational Psychology, Vol. 78, pp. 531-51.

Arthur, J. (1994), "Effects of human resource systems on manufacturing performance and turnover", Academy of Management Journal, Vol. 37, pp. 670-87.

Australian Bureau of Statistics (ABS) (2001), Our Changing Work Profile, Australian Capital Territory, Canberra.

Barney, J. and Wright, P. (1998), "On becoming a strategic partner: the role of human resources in gaining competitive advantage", Human Resource Management, Vol. 37, pp. 31-46.

Bassi, L.J. and Van Buren, M.E. (1999), "Sharpening the leading edge", Training \& Development, Vol. 53, pp. 23-32.

Bayazit, M. and Mannix, E.A. (2003), "Should I stay or should I go? Predicting team members' intent to remain in the team", Small Group Research, Vol. 34, pp. 290-321.

Beck, S. (2001), "Why associates leave, and strategies to keep them", New Jersey Law Journal, March 26, p. 31.

Becker, T.E. and Billings, R.S. (1993), "Profiles of commitment: an empirical test", Journal of Organizational Behavior, Vol. 14, pp. 177-90.

Becker, B. and Gerhart, B. (1996), "The impact of human resource management on organizational performance: progress and prospects", Academy of Management Journal, Vol. 39, pp. 779-801.

Black, S.E. and Lynch, L.M. (1996), "Human capital investments and productivity", American Economic Review, Vol. 86, pp. 263-8.

Blau, P.M. (1964), Exchange and Power in Social Life, Wiley, New York, NY.

Boyd, B.K. and Salamin, A. (2001), "Strategic reward systems: a contingency model of pay system design", Strategic Management Journal, Vol. 22, pp. 777-93.

Bretz, R.D. and Judge, T.A. (1994), "Person-organization fit and the theory of work adjustment: implications for satisfaction, tenure, and career success", Journal of Vocational Behavior, Vol. 44, pp. 32-54.

Broadfoot, L.E. and Ashkanasy, N.M. (1994), "A survey of organizational culture measurement instruments", paper presented at the Annual General Meeting of Australian Social Psychologists, Cairns, April.

Cable, D.M. and Judge, T.A. (1997), "Interviewers' perceptions of person organization fit and organizational selection decisions", Journal of Applied Psychology, Vol. 82, pp. 546-61.

Cammann, C., Fichman, M., Jenkins, D. and Klesh, J. (1979), "The Michigan organizational assessment questionnaire", unpublished manuscript, University of Michigan, Ann Arbor, MI.

Chatman, J.A. (1991), "Matching people and organization: selection and socialization in public accounting firms", Administrative Science Quarterly, Vol. 36, pp. 459-84.

Chen, T.Y., Chang, P.L. and Yeh, C.W. (2004), "Research note: a study of career needs, career development programs, job satisfaction and the turnover intentions of R\&D personnel", Career Development International, Vol. 9, pp. 424-37. 
Clarke, K.F. (2001), "What businesses are doing to attract and retain employee - becoming an employer of choice", Employee Benefits Journal, March, pp. 34-7.

Das, H. (2002), "The four faces of pay: an investigation into how Canadian managers view pay", International Journal of Commerce \& Management, Vol. 12, pp. 18-41.

Davies, R. (2001), "How to boost staff retention", People Management, Vol. 7, pp. 54-6.

Detoro, I. and McCabe, T. (1997), "How to stay flexible and elude fads?", Quality Progress, Vol. 30, pp. 55-61.

Eisenberger, R., Fasolo, P. and Davis-LaMastro, V. (1990), "Perceived organizational support and employee diligence, commitment, and innovation", Journal of Applied Psychology, Vol. 75, pp. 51-9.

Erdogan, B. and Bauer, T.N. (2005), "Enhancing career benefits of employee proactive personality: the role of fit with jobs and organizations", Personnel Psychology, Vol. 58, pp. 859-91.

Ferguson, W. (1990), "Creative compensation: keeping employees on board", Journal of Property Management, Vol. 55, pp. 12-16.

Ferris, G.F., Hochwarter, W.A., Buckley, R.M., Harrel-Cook, G. and Frink, D.D. (1999), "Human resources management: some new directions", Journal of Management, Vol. 25, pp. 385-8.

Finegan, J.E. (2000), "The impact of person and organizational values on organizational commitment", Journal of Occupational \& Organizational Psychology, Vol. 73, pp. 149-69.

Frank, R.H. and Cook, P.J. (1995), The Winner-take-all Society, The Free Press, New York, NY.

Frazis, H., Gittleman, M., Horrigan, M. and Joyce, M. (1998), "Results from the 1995 survey of employer-provided training", Monthly Labor Review, Vol. 121, pp. 3-14.

Furnham, A. (2002), "Work in 2020 prognostications about the world of work 20 years into the millennium", Journal of Managerial Psychology, Vol. 15, pp. 242-50.

Gold, M. (2001), "Breaking all the rules for recruitment and retention", Journal of Career Planning and Employment, Vol. 61, pp. 6-8.

Goldstein, I. (1991), "Training in organizations", in Dunnette, M.D. and Hough, L.M. (Eds), Handbook of Industrial and Organizational Psychology, 2nd ed., Consulting Psychologists Press, Palo Alto, CA, pp. 507-619.

Gomez-Mejia, L.R., Balkin, D.B. and Cardy, R.L. (1995), Managing Human Resources, Prentice-Hall, Englewood Cliffs, NJ.

Hackman, J. and Oldham, G. (1975), "Development of the job diagnostic survey", Journal of Applied Psychology, Vol. 60, pp. 159-70.

Hollenbeck, J.R. (1989), "Control theory and the perception of work environments: the effects of focus of attention on affective and behavioral reactions to work", Organizational Behavior and Human Decision Processes, Vol. 43, pp. 406-30.

Huang, I.C., Lin, H.C. and Chuang, C.H. (2006), "Constructing factors related to worker retention", International Journal of Manpower, Vol. 27, pp. 491-508.

Huang, M.P., Cheng, B.S. and Chou, L.F. (2005), "Fitting in organizational values: the mediating role of person-organization fit between CEO charismatic leadership and employee outcomes", International Journal of Manpower, Vol. 26, pp. 35-50.

Idaszak, J.R. and Drasgow, F. (1987), "A revision of the job diagnostic survey: elimination of a measurement artifact", Journal of Applied Psychology, Vol. 72, pp. 69-74.

Jackson, S.E. and Schuler, R.S. (1995), "Understanding human resource management in the context of organizations and their environments", in Spence, J.T., Darley, J.M. and Foss, D.J. (Eds), Annual Review of Psychology, Vol. 46, Annual Reviews, Palo Alto, CA, pp. 237-64. 
Jardine, E. and Amig, S. (2001), "Managing human capital", Behavioral Health Management, Vol. 21, pp. 25-31.

Jones, R., Sanchez, J., Parameswaran, G., Phelps, J., Shoptaugh, C., Williams, M. and White, S. (2001), "Selection or training? A two-fold test of the validity of job-analytic ratings of trainability", Journal of Business and Psychology, Vol. 15, pp. 363-89.

Kanfer, R.M. and Heggestad, E.D. (1997), "Motivational traits and skills: a person-centered approach to work motivation", in Cummings, L.L. and Straw, B.M. (Eds), Research in Organizational Behavior, Vol. 19, JAI Press, Greenwich, CT, pp. 1-57.

Kemske, F. (1998), "HR 2008: a forecast based on our exclusive study", Workforce, Vol. 77, pp. $46-58$.

Kochan, T. and Osterman, P. (1994), The Mutual Gains Enterprise, Harvard Business School Press, Boston, MA.

Kraut, J. and Korman, P. (1999), Evolving Practices in HRM, Jossey-Bass, San Francisco, CA.

Kristof, A.L. (1996), "Person-organization fit: an integrative review of its conceptualizations, measurement, and implications", Personnel Psychology, Vol. 49, pp. 1-49.

Kristof-Brown, A., Zimmerman, R.D. and Johnson, E.C. (2005), "Consequences of individuals' fit at work: a meta-analysis of person-job, person-organization, person-group, and person-supervision fit", Personnel Psychology, Vol. 58, pp. 281-342.

Lauri, B., Benson, G. and Cheney, S. (1996), "The top ten trends", Training \& Development, Vol. 11, pp. 28-42.

Lauver, K.J. and Kristof-Brown, A. (2001), "Distinguishing between employees' perceptions of person-job and person-organization fit", Journal of Vocational Behavior, Vol. 59, pp. 454-70.

Lee, T.W., Ashford, S.J., Walsh, J.P. and Mowday, R.T. (1992), "Commitment propensity, organizational commitment, and voluntary turnover: a longitudinal study of organizational entry processes", Journal of Management, Vol. 18, pp. 15-26.

Linstone, H.F. and Turoff, M. (1975), The Delphi Method: Technique and Applications, Addison-Wesley, Reading, MA.

Lyons, TF. (1971), "Role clarity, need for clarity, satisfaction, tension and withdrawal", Organizational Behavior and Human Performance, Vol. 8, pp. 99-110.

McCallum, J.S. (1988), "Involving business", Ivey Business Quarterly, Vol. 62, pp. 65-8.

Marchington, M. and Wilkinson, A. (1997), Core Personnel and Development, Institute of Personnel and Development, London.

Mercer Report (2003), "Mercer study raises red flags for employer pay and benefit plans (findings of the 2002 People at work survey)", Human Resource Department Management Report, May, pp. 8-15.

Messmer, M. (2000), "Orientation programs can be key to employee retention", Strategic Finance, Vol. 81, pp. 12-15.

Meyer, J.P., Stanley, D.J., Herscovitch, L. and Topolnytsky, L. (2002), "Affective, continuance, and normative commitment to the organization: a meta-analysis of antecedents, correlates, and consequences", Journal of Vocational Behavior, Vol. 61, pp. 20-52.

Mowday, R.T., Steers, R.M. and Porter, L.W. (1979), "The measurement of organizational commitment", Journal of Vocational Behavior, Vol. 14, pp. 224-47.

Netemeyer, R.G., Boles, J.S., McKee, D.O. and McMurrian, R. (1997), “An investigation into the antecedents of organizational citizenship behaviors in a personal selling context", Journal of Marketing, Vol. 61, pp. 85-98. 
Oakland, S. and Oakland, J.S. (2001), "Current people management activities in world-class organizations", Total Quality Management, Vol. 12, pp. 773-9.

O'Reilly, C. III and Chatman, J. (1986), "Organizational commitment and psychological attachment: the affective compliance, identification, and internalization on pro-social behavior", Journal of Applied Psychology, Vol. 71, pp. 493-7.

O'Reilly, C.A., Chatman, J. and Caldwell, D.F. (1991), "People and organizational culture: a profile comparison approach to assessing person-organization fit", Academy of Management Journal, Vol. 34, pp. 487-516.

Paré, G. and Tremblay, M. (2007), "The influence of high-involvement human resources practices, procedural justice, organizational commitment, and citizenship behaviors on information technology professionals' turnover intentions", Group \& Organization Management, Vol. 32, pp. 326-57.

Park, R., Erwin, P.J. and Knapp, K. (1997), "Teams in Australia's automotive industry: characteristics and future challenges", International Journal of Human Resource Management, Vol. 8, pp. 780-96.

Parker, O. and Wright, L. (2000), "Pay and employee commitment: the missing link", Ivey Business Journal, Vol. 65, pp. 70-9.

Peterson, S.L. (2004), "Toward a theoretical model of employee turnover: a human resource development perspective", Human Resource Development Review, Vol. 3, pp. 209-28.

Pfeffer, J. (1994), Competitive Advantage through People: Unleashing the Power of the Work Force, Harvard Business School Press, Boston, CA.

Pfeffer, J. (1998), "Seven practices of successful organizations", California Management Review, Vol. 40, pp. 96-125.

Phillips, R. (1997), "New measures for business", Measuring Business Excellence, Vol. 1, pp. 4-7.

Pil, F.K. and Macduffie, J.P. (1996), "The adoption of high involvement work practices", Industrial Relations, Vol. 35, pp. 423-55.

Preuss, G.A. and Lautsch, B.A. (2002), "The effect of formal versus informal job security on employee involvement programs", Relations Industrielles, Vol. 57, pp. 517-39.

Price, J.L. and Mueller, C. (1981), "A causal model of turnover for nurses", Academy of Management Journal, Vol. 24, pp. 543-65.

Reichers, A.E. (1985), "A review of reconceptualization of organizational commitment", Academy of Management Review, Vol. 10, pp. 465-76.

Roberts, J.A., Coulson, K.R. and Chonko, L.B. (1999), "Salesperson perceptions of equity and justice and their impact on organizational commitment and intent to turnover", Journal of Marketing Theory and Practice, Vol. 7, pp. 1-15.

Schnake, M.E., Williams, R.J. and Fredenberger, W. (2007), "Relationships between frequency of use of career management practices and employee attitudes, intention to turnover, and job search behavior", Journal of Organizational Culture, Communication and Conflict, Vol. 11, pp. 53-64.

Schneider, B. (1987), “The people make the place", Personnel Psychology, Vol. 40, pp. 437-53.

Schneider, B., Goldstein, H.W. and Smith, D.B. (1995), "The ASA framework: an update", Personnel Psychology, Vol. 48, pp. 747-73.

Seashore, S.E., Lawler, E.E., Mirvis, P. and Cammann, C. (1982), Observing and Measuring Organizational Change: A Guide to Field Practice, Wiley, New York, NY. 
Setton, R.P., Bennett, N. and Liden, R. (1996), "Social exchange in organizations: perceived organizational support, leader-member exchange, and employee reciprocity", Journal of Applied Psychology, Vol. 81, pp. 219-27.

Shepherd, J.L. and Mathews, B.P. (2000), "Employee commitment: academic vs practitioner perspectives", Employee Relations, Vol. 22, pp. 555-75.

Sheridan, J.E. (1992), "Organizational culture and employee retention", Academy of Management Journal, Vol. 35, pp. 1036-57.

Stein, N. (2000), "Winning the war to keep top talent: yes you can make your workplace invincible!", Fortune, Vol. 141, p. 132.

Storey, J. and Sisson, K. (1993), Managing Human Resources and Industrial Relations, Open University Press, Buckingham.

Sturges, J., Conway, N., Guest, D. and Liefooghe, A. (2005), "Managing the career deal: the psychological contract as a framework understanding career management, organizational commitment and work behavior", Journal of Organizational Behavior, Vol. 26, pp. 821-38.

Taplin, I.M. and Winterton, J. (2007), "The importance of management style in labour retention", International Journal of Sociology \& Social Policy, Vol. 27, pp. 5-18.

Trank, C.Q., Rynes, S.L. and Bretz, R.D. Jr (2002), "Attracting applicants in the war for talents: differences in work preferences among high achievers", Journal of Business and Psychology, Vol. 16, pp. 331-45.

Tsui, A.S., Pearce, J.L., Porter, L.W. and Tripoli, A.M. (1997), "Alternative approaches to the employee-organization relationship: does investment in employees pay off?", Academy of Management Journal, Vol. 40, pp. 1089-121.

Udo, G.J., Guimaraes, T. and Igbaria, M. (1997), "An investigation of the antecedents of turnover intention for manufacturing plant managers", International Journal of Operations \& Production Management, Vol. 17, pp. 912-30.

Van Vianen, A.E.M. (2000), "Person organization fit: the match between newcomers and recruiters preferences for organizational cultures", Personnel Psychology, Vol. 53, pp. 113-22.

Vandenberghe, C. (1999), "Organizational culture, person-culture fit, and turnover: a replication in the health care industry", Journal of Organizational Behavior, Vol. 20, pp. 175-84.

Vorhies, D.W. and Harke, M. (2000), "The capabilities and performance advantages of market-driven firms: an empirical investigation", Australian Journal of Management, Vol. 25, pp. 145-54.

Walker, J.W. (2001), "Perspectives", Human Resource Planning, Vol. 24, pp. 6-10.

Wetland, D. (2003), "The strategic training of employees model: balancing organizational constraints and training content", S.A.M. Advanced Management Journal, Vol. 68, pp. $56-63$.

Withers, P. (2001), "Retention strategies that respond to worker values", Workforce, Vol. 80, pp. 37-44.

Whitener, E.M. (2001), "Do 'high commitment' human resource practices affect employee commitment? A cross-level analysis using hierarchical linear modeling", Journal of Management, Vol. 27, pp. 515-64.

Wiens-Tuers, B.A. (2001), "Employee attachment and temporary workers", Journal of Economic Issues, Vol. 35, pp. 242-50.

Willis, C. (2000), "Go for your goals", Working Woman, March, pp. 6-7. 
Wood, S. (1999), "Human resource management and performance", International Journal of Management Review, Vol. 1, pp. 367-413.

Wood, S. and De Menezes, L. (1998), "High commitment management in the UK: evidence from the workplace industrial relations survey and employers' manpower and skills practices survey", Human Relations, Vol. 51, pp. 415-85.

Workman, M. and Bommer, W. (2004), "Redesigning computer call center work: a longitudinal field experiment", Journal of Organizational Behavior, Vol. 25, pp. 317-37.

Youndt, M.A., Snell, S.A., Dean, J.W. and Lepak, D.P. (1996), "Human resource management, manufacturing strategy, and firm performance", Academy of Management Journal, Vol. 39, pp. 836-65.

\section{Further reading}

Noe, R.A. (1999), Employee Training \& Development, Irwin McGraw Hill, New York, NY.

\section{Appendix}

Human resource factors

The collective responses identified the human resource (HR) factors/elements as shown in Table AI, which influence the retention of permanent employees. Please rank the top five factors in order of their importance, with 1 being the most important ().

\section{Interview questions}

(1) The following list has been identified by research as the top five $\mathrm{HR}$ factors that influence retention. Please indicate the extent of their importance to your company with regards to the retention of your employees (e.g. very important, important, somewhat important):

- effective selection;

- reward and recognition of employee value;

- career development;

- challenging employment assignments and opportunities; and

- equity of compensation and benefits.

(2) How are the HR factors managed?

- Could they be done better?

- What impact do they have on staff retention?

Human resource factors

Rank

A. Equity of compensation and benefits

B. Effective selection

C. Provision of effective training

D. Career development

E. Challenging employment structures and opportunities

F. Fair and equitable performance management

G. Employee assistance programs

H. Security of tenure

I. Reward and recognition of employee value

J. Employee behavior education (e.g. OHS and EEO)

Table AI. 